\title{
One clinician's journey - a retreat from 'the front line'
}

\author{
B. Murchie $^{1}$
}

\section{In brief}

Demonstrates the author's unconventional journey from general practice, completing a masters degree and eventually returning to the hospital environment at a later stage of life.
Aims to help others avoid some of the mistakes the author made.

Highlights other options available to clinicians within and outside of dentistry.

Whether the clinician has recently qualified or graduation day is a distant memory, it is important for him/her to be aware of the alternative options available outside of the general practice setting as these are not always fully explained. It is essential that one enjoys their career choice when even a brief consideration is given to the length of time that one will spend at work and thinking about work, including the additional hours spent in the workplace for countless other reasons. The author worked as a general dental practitioner for several years at different practices. However, dissatisfaction with the daily routine eventually led to a crossroads and a new chapter of his professional career blossomed at a later stage in life. This article is aimed at undergraduates and postgraduates alike, so that others can learn from the author's unconventional career pathway.

When I first qualified from university as an undergraduate, all I could foresee was an apparently care free and uncomplicated life stretching ahead of me on a clearly defined course. While fully prepared to work hard and become a trusted professional, I still felt that I would eventually settle into a safe and comfortable routine. A 9 am till 5 pm career, working five days per week and the prospect of the occasional on-call rota shifts, which did not overly concern me. My patients would be an easy going group of people and would mostly be pleased and grateful that I could help relieve their suffering, with the occasional thank you card for my hard efforts. The most important thing was that I had achieved my dream and graduated. The honorary title of 'Doctor' was mine and I could finally set sail into the smooth, uncharted world of general dentistry. Interestingly, at this particular point in my

${ }^{1} \mathrm{SHO}$ in Restorative Dentistry, Newcastle Dental Hospital, Newcastle Upon Tyne, NE2 4AZ

Correspondence to: B. Murchie

Email: bryandm87@yahoo.com

Refereed Paper. Accepted 20 December 2016

DOI: 10.1038/sj.bdj.2017.69

${ }^{\odot}$ British Dental Journal 2017; 222: 76-78 life, the only form of experience I had gained, with respect to the general dental practitioner (GDP), were short and infrequent visits to observe their daily routine practice in my fifth (and final) year. Myth and hearsay must have also been a prevailing factor that was protecting my idyllic dream, because when I look back in quiet horror of how naive I was, it is obvious that I lacked any real insight into this new and challenging world. I am sure many can relate to the late nights in the library studying and desperate attempts to obtain the suitable number of patient cases to qualify, therefore, what would come after graduation day was at the furthest recesses of my mind.

During the first post-graduate year, I began my one year vocational training programme; of course there is the alternative option of the two year training scheme which intertwines hospital with general practice. Throughout this time I encountered strange, if not, uncharted lands. I felt that the practice setting was much more hands-on and pressured compared to the relatively relaxed demeanour of secondary care that I was used to. However, I was undeterred, my faith did not falter and I kept steadfast to my compass which was set for the final destination of 'fully qualified GDP'.
The training year passed without concern, it was a well-organised programme and I was adequately supervised with a good support network. The transitional phase from hospital to practice was now finished and I felt ready to take on the new challenges ahead. The only problem now was that there was no longer any back up and I was the captain of this ship. Almost as if with immediate effect the dynamics of my situation dramatically changed. The trainer no longer came in to the surgery to check my work, see I was surviving ok or even to bring me the occasional cup of coffee. I was now an official member of the GDP club and it felt both exciting and a little daunting in the same instance.

The first wake up call to my new found situation came to light when a fixed-fixed bridge prosthesis, which I had recently fitted, did not entirely meet the patient's very high expectations. The senior GDP came in and very briefly looked at the case, but no longer gave the advice and guidance I had come to naturally expect. This sparked a new dilemma, if I did not know the answer then there was no one wanting, nor willing, to take on board a case filled with potentially hazardous consequences. This was not a teaching hospital, it 
was a job and the next two patients were sitting eagerly in the waiting room. I had arrived at my destination; however, the island was not as big or fruitful as it had appeared from a distance and I had definitely overlooked the nearby medico-legal locker bay with dangerously lethal rip tides concealed within the water and inhabited by litigious sharks.

Over the coming months and years I kept tirelessly pushing ahead with my original agenda. I assumed that things must improve if I was determined enough and continually gave it my best each and every day. While general practice has many plus points and luxuries not afforded in other careers, for some unknown reason it did not suit my personality traits, despite what appeared to fulfil all my criteria on paper. When you take into consideration a normal 40 hour working week and that most people will be in their career for a minimum of 30 years, it is important to positively connect with that dominating aspect of your life. This overwhelming thought, among many others, was initially shrugged off as nonsense and a natural reaction to all the recent changes in my life. However, over time, the doubts grew and grew, which eventually evolved to a point where I could not ignore them any further. In these situations, a practitioner can opt for one of many different routes (Box 1). Unbeknown to me at the time, I would eventually change my bearing and choose the option which would end up with me turning back to where I came from, namely the dental hospital.

I elected to do some research around this issue and I decided to embark on a part time (and hugely expensive) post-graduate programme. During this time I began to truly appreciate the value of knowledge, which I had underestimated in the earlier undergraduate years. I slowly took note of the obvious facts, which was when someone else imparts their wisdom, it is a blue print crafted from an accumulation of all the past mistakes made by themselves and others before them. All the relevant solutions are then presented in an easily understood manner, which can be used to successfully negotiate the rough tides ahead and avoid the pearls of the deep (if you take notice and appreciate the value of experience!). This knowledge had a huge impact on me as a clinician and I knew then that something greater was happening at this moment, which went far beyond what I had initially anticipated. I now had a new set of coordinates and a reinvigorated mindset, which I would follow even if it meant reaching the edge of the flat world.

\section{Box 1 Dental career options within and outside of general practice}

\section{Key point}

If one finds themselves contemplating life outside of dentistry in general practice, or simply want a change to their daily routine, then they are faced with the following options (please note that these have not been listed in any particular order):

- Full time post in secondary and/or tertiary dental care - all specialties are a minimum of 3 years via StR training posts, this includes the 13 specialties recognised by the GDC:1

- Paediatric dentistry

- Dental public health

- Restorative dentistry

- Prosthodontics

- Orthodontics

- Periodontics

- Endodontics

- Oral Surgery

- Oral medicine

- Special care dentistry

- Oral microbiology

- Oral and maxillofacial radiology

- Oral and maxillofacial pathology

- Part time role in secondary care, such as visiting GDP teaching undergraduates.

- Privately funded speciality training. This includes an MSc or MClinDent course which covers a wide range of dental specialties. However, they are more limited and do not include oral medicine, oral microbiology, oral and maxillofacial pathology/radiology or special care dentistry. Consideration must also be given to funding, where courses generally last 2 to 3 years and tuition fees range from $f 14,000$ to $f 50,000 .{ }^{2}$

- Change in career - This may include training to become oral and maxillofacial surgeon (OMFS) which is considered a medical speciality. One may even decide that they wish to follow a career pathway in medicine instead.

- Another alternative is to contemplate a career entirely unrelated to dentistry or medicine.

- Consider the business aspects of general dentistry, for example buying and maintaining a practice.

- Make changes within the general practice - It may be an option to consider focusing more on the clinical areas which excite you most. This may be complimented with a part-time post-graduate training programme to further enhance your skills and learning.

It is important to reflect on the advantages and disadvantages of each, such as the associated costs, time factors and commitment levels required. It has to be practical and achievable without setting yourself up for failure. Remember that no one career pathway has any value over the others, it is a personal decision.

A good source for further information on postgraduate specialty training in the UK is The Dental Gold Guide. ${ }^{3}$

This made sense to me; so much so that once I had graduated with distinction I did not have the passion to go back to my old routine in general practice. Pandora's Box was opened and life could not continue as it had before. On one side, I had the easy life I always thought I wanted along with money and a predictable routine, but this was tainted with many risks and uncertainties. Whereas, on the other hand there was the huge gamble of moving city (or even country), the much reduced salary and potentially losing status and control of my clinical environment. Furthermore, I was slightly older now and considered whether this would play a role in the psychological game, where I could be the oldest one surrounded by much younger trainees.

I decided it was worth the risk and I was very fortunate to be accepted for a hospital post of my choice. Gathering together with my newly acquired wisdom and understanding of the world I ran at this opportunity with both arms wide open. Within a few months of the new training position, I sat in pensive thought after a long consultation clinic. It had been a long day, I had a large pile of letters to dictate and all my patients had been challenging cases referred from the surrounding general practices. Only one thought ran through my head as I sat in the quiet of the night with only the vague sound of students in the background discussing their patient cases. I questioned why I had not done this sooner. It became clear, it all led back to my undergraduate days and the assumptions that I had wrongly made based on my own beliefs, not facts and experiences.

With hindsight, I should have considered all the aspects of dentistry from day one. It was my mistake, no one else's. I could try to point 
the finger, but it would be in vain and without any purpose or reason. I could take solace in the fact that I had found my calling in the end, with perhaps a much greater appreciation for the equipment, time and expertise that I had secretly craved all those years. They always said life was never a straight line from A to Z, but I never thought I would be one of the people to fall into that category because I had my 'perfect' plan. Like a child who thinks that they are invincible and has no concept of fear or the consequences of their actions. I too strode out of that dental hospital unaware of the impact my choices would have on my long-term career and happiness. Money and predictability are not for everyone, as unbelievable as that phrase may sound, it is the truth.

In summary, there is precious little guidance out there for newly qualified dentists in terms of managing their long-term expectations in the general practice setting. I have presented this short story to you and if it helps even one person contemplate their life choices at an earlier stage in their life then this article has been worth it. The overall message I wish to convey is sometimes what sounds like an ideal plan and what works for the majority, is not necessarily right for you. Be realistic, look at your character traits and what drives you to get up out of that warm bed every morning. If you strive to learn and teach with a desire to be a part of a bigger team then hospital may be your destiny. Alternatively, if this is not the case then general practice may be your calling. Remember that either option is perfectly acceptable with there being no ideal career pathway. It is of the author's opinion that a young graduate should experience both clinical environments and make an informed decision.
Therefore, it may be wise to consider the two-year training programme immediately after qualification. It is recommended to have a full appreciation for the role primary, secondary and tertiary care have in the NHS system, as one could not survive without the other.

Let's make one thing clear, general practitioners are the specialists of their field. However, not everyone can last under the constant fire which they endure on a daily basis and that is one of the reasons why I chose to retreat from primary care, or as I call it, 'the front line'.

1. GDC. Specialist lists. Available online at http://www. gdc-uk.org/Dentalprofessionals/Specialistlist/Pages/ default.aspx (accessed January 2017).

2. Critchlow $S$, Nanayakkara L. A guide to entry into speciality training. Br Dent J 2012; 212: 35-40.

3. COPDEND. The Dental Gold Guide. Available online at http://copdend.org/content.aspx?Group=Home\&Page=Downloads_DGG (accessed January 2017). 